months. Rheumatoid Factor (RF) positivity and higher baseline fatigue were associated with high symptoms at 6months; decreasing ESR from 6 to 12-months was associated high symptoms at 12months, and having high symptoms at 12-months, along with reduced Swollen Joint Count (SJC), CRP and MCS from month 12 to 18 was associated with high symptoms at 18 -months.

Conclusion: Tight treatment control resulted in controlled Inflammation by 6-months, resulting in just two main patient sub-groups; those with low and high P\&PS. Over one-third of patients experienced high pain and psychological symptoms. Membership of the high symptom group was associated with RF positivity but was mainly driven by prior symptom experience. Whilst inflammatory control remains a primary target, other treatments targeting pain, fatigue and mental health must be considered to reduce the burden of disease.

Disclosure of Interests: Lewis Carpenter: None declared, Katie Bechman: None declared, Andrew Cope: None declared, Elena Nikiphorou: None declared, James Galloway Consultant for: Pfizer Inc, Sam Norton: None declared

DOI: 10.1136/annrheumdis-2019-eular.7727

\section{SAT0080 COMPARISON OF INFLAMMATORY CYTOKINES LEVELS IN RHEUMATOID ARTHRITIS WITH CAROTID PLAQUE; CASE-CONTROL STUDY}

Karla Paola Cuéllar-Calderón ${ }^{1}$, Dionicio Ángel Galarza-Delgado ${ }^{1}$, José Ramón Azpiri-López ${ }^{2}$, Iris Jazmin Colunga-Pedraza ${ }^{2}$, Ileana Cecilia ReynosaSilva $^{1}$, Marielva Castro-González ${ }^{1}$, Carolina Marlene Martínez-Flores ${ }^{2}$, Raymundo Pineda', Gisela García-Arellano ${ }^{1}$, Rosa Arivizú Rivera ${ }^{1} .{ }^{1}$ Hospital Universitario Dr José Eleuterio Gonzalez, Rheumatology, Monterrey, Mexico;

${ }^{2}$ Hospital Universitario Dr José Eleuterio Gonzalez, Cardiology, Monterrey, Mexico

Background: There is a $50 \%$ increase in cardiovascular mortality in RA compared to controls. Chronic inflammation causes endothelial dysfunction and accelerated atherosclerosis. Key molecular pathways in this process are dependent on cytokines like TNF- $\alpha$, IL-1, IL-6, among others, which are shared with RA. Increased disease activity could contribute to atherosclerosis. Carotid ultrasound (US) has recently been recommended as a screening tool for early detection of subclinical atherosclerosis.

Objectives: To compare different cytokines between Mexican-mestizo RAsubjects with/without carotid plaque (CP).

Methods: An observational cross-sectional trial was designed. Inclusion criteria: age between 40-75 years old, fulfillment of the 2010 ACR/EULAR classification criteria, and detection of a CP during a carotid US. Subjects with a prior diagnosis of cardiovascular disease or a poor US window were excluded. RA subjects were matched to controls (RA patients without $\mathrm{CP}$ ) by age and cardiovascular (CV) comorbidities. Every subject had a carotid US performed; reviewed by two board-certified radiologists. Cytokines measured were IL-1, IL-6, TNF- $\alpha$, VCAM-1, ICAM-1 and MMP9, using an ELISA reader (Glomax E9032). Descriptive analysis was done with frequencies (\%), median (q25-q75), and comparisons between groups with Chi square test and Mann U Whitney's test.

Results: 71 subjects were included, 95.8\% were females, with a median age of 58 years (54-65). Levels of cytokines in Table 1. Comparisons between groups are in Table 2. Groups were well balanced, with no differences in CV comorbidities $(p>0.05)$. No significant differences among cytokine levels regarding CP were found. Subjects in remission $(n=12$, $33 \%)$ had a lower prevalence of CP ( $p<0.05$, OR: $0.3 ; 95 \% \mathrm{Cl}: 0.1-0.9)$ and a lower median IL-1 level than those with higher disease activity $(p<0.05)$. No significant differences were found among any other of the compared cytokines.

Table 1. Cytokines levels

\begin{tabular}{lc}
\hline & Median(q25-q75) \\
\hline IL1, pg/ml & $8.1(6.6-9.6)$ \\
TNF-a, pg/ml & $76(61-101)$ \\
IL6, pg/ml & $4.4(4.1-4.8)$ \\
ICAM, $\mathrm{ng} / \mathrm{ml}$ & $91(61-141)$ \\
VCAM, ng/ml & $56.5(41.3-65.1)$ \\
MMP9, pg/ml & $811(721-931)$ \\
\hline
\end{tabular}

Table 2. Clinical characteristics.

\begin{tabular}{|c|c|c|c|}
\hline Variable & $\begin{array}{c}\text { CP } \\
(n=37)\end{array}$ & $\begin{array}{l}\text { No } C P \\
(n=34)\end{array}$ & $p$ \\
\hline Age, years median (q25-q75) & $\begin{array}{c}59.2(54.8- \\
66.1)\end{array}$ & $57.7(53-61.2)$ & NS \\
\hline Female, n (\%) & $35(94.6)$ & $33(97.1)$ & NS \\
\hline Dyslipidemia, n (\%) & 7 (18.9) & $6(17.6)$ & NS \\
\hline T2DM, n (\%) & $10(27)$ & $7(20.6)$ & NS \\
\hline Hypertension, n (\%) & $12(32.4)$ & $10(29.4)$ & NS \\
\hline BMI, median (q25-q75) & $29(26.5-31.1)$ & $\begin{array}{l}27.9(24.6- \\
33.2)\end{array}$ & NS \\
\hline Disease duration, media \pm SD & $12.4 \pm 9.9$ & $10.6 \pm 9$ & NS \\
\hline DAS28 CRP, median (q25-q75) & $2.9(1.5-3.9)$ & $2.39(1.8-3.1)$ & NS \\
\hline MTX n, (\%) & $17(45.9)$ & $22(64.7)$ & NS \\
\hline Prednisone, n (\%) & $27(73)$ & $24(70.6)$ & NS \\
\hline IL-1 pg/ml, median (q25-q75) & $8.7(6.7-10.1)$ & $7.9(6.1-9.3)$ & NS \\
\hline TNF-a pg/ml, median (q25-q75) & $76(61-101)$ & $76(61-96)$ & NS \\
\hline IL-6 pg/ml, median (q25-q75) & $4.4(4.1-4.9)$ & $4.4(3.9-4.8)$ & NS \\
\hline ICAM ng/ml, median (q25-q75) & $91(61-118.5)$ & $83.5(61-217.2)$ & NS \\
\hline VCAM ng/ml, median (q25-q75) & $\begin{array}{c}58.1(42.1- \\
64.8)\end{array}$ & $\begin{array}{c}54.3(35.1- \\
65.9)\end{array}$ & NS \\
\hline MMP9 pg/ml, median (q25-q75) & $\begin{array}{l}811(711- \\
938.5)\end{array}$ & $\begin{array}{l}821(724.7- \\
931)\end{array}$ & NS \\
\hline $\begin{array}{l}\text { Remission (DAS 28-CRP<2.6), n } \\
(\%)\end{array}$ & $12(33.3)$ & $20(58.8)$ & 0.032 \\
\hline
\end{tabular}

Conclusion: In our cohort subjects in remission had a lower prevalence of $\mathrm{CP}(\mathrm{OR}=0.3,0.1-0.9)$. No difference was found between cytokines regarding $\mathrm{CP}$. Subjects with active disease had a higher level of IL-1 than subjects in remission. To our best knowledge, this is the first study to evaluate levels of cytokines in Mexican RA-subjects.

\section{REFERENCES}

[1] López R, et al. Cardiovascular risk assessment in patients with rheumatoid arthritis. Autoimmun Rev 2016.

[2] Pasceri V, et al. A tale of two diseases: Atherosclerosis and rheumatoid arthritis Circulation 1999.

Disclosure of Interests: None declared

DOI: 10.1136/annrheumdis-2019-eular.4980

\section{SAT0081 BOTH OVERFAT AND MYOPENIA ARE ASSOCIATED WITH PHYSICAL DYSFUNCTION IN RHEUMATOID ARTHRITIS PATIENTS}

Chutao Chen, Jian-Zi Lin, Lijuan Yang, LI Qian-Hua, MA Jianda, Le-Feng Chen, Yingqian Mo, Lie Dai. Sun Yat-sen Memorial Hospital, Sun Yat-sen University, Department of Rheumatology, Guangzhou, China

Background: Comprehensive disease control has been recommended by EULAR guidelines for rheumatoid arthritis (RA) which includes simultaneous achievement of stringent control of the signs and symptoms of inflammation, the absence of radiographic progression and normal physical function. Identifying those patients at high risk of disability at a sufficiently early stage of their disease course presents a major challenge. The associations of body mass index (BMI) and body composition (BC) with physical activity function in RA patients still obscure.

Objectives: To investigate the characteristics of BC and BMI in RA patients and their association with physical activity function.

Methods: Consecutive RA patients were recruited and clinical data including disease activity, function and radiographic assessment were collected BC was assessed by bioelectric impedance analysis. Overfat was defined by body fat percentage (BF\%) as $\geq 25 \%$ for men and $\geq 35 \%$ for women. Myopenia was defined by appendicular skeletal muscle mass index (ASMI) $\leq 7.0 \mathrm{~kg} / \mathrm{m}^{2}$ in men and $\leq 5.7 \mathrm{~kg} / \mathrm{m}^{2}$ in women. Subjects were categorized by $\mathrm{BMI}$ as underweight $\left(\mathrm{BMl}<18.5 \mathrm{~kg} / \mathrm{m}^{2}\right)$, normal weight (18.5 $\left.\mathrm{kg} / \mathrm{m}^{2} \leq \mathrm{BMl}<24 \mathrm{~kg} / \mathrm{m}^{2}\right)$, overweight $\left(24 \mathrm{~kg} / \mathrm{m}^{2} \leq \mathrm{BMl}<28 \mathrm{~kg} / \mathrm{m}^{2}\right)$ and obese $\left(\mathrm{BMI} \geq 28 \mathrm{~kg} / \mathrm{m}^{2}\right)$ according to Chinese criteria. Physical dysfunction was defined by $\mathrm{HAQ}-\mathrm{DI} \geq 0.5$.

Results: There were 516 RA patients (mean age $49.8 \pm 12.9$ years old with $83 \%$ women) recruited, and $37 \%$ with physical dysfunction. Compared with those with normal physical function, RA patients with physical dysfunction 
were older with longer disease duration, and had higher disease activity indicators including timing of morning stiffness, 28TJC, 28SJC, PtGA, PrGA, PainVAS, ESR, CRP, DAS28-CRP, SDAl and CDAl, as well as higher radiographic assessment including $\mathrm{mTSS}$, JSN subscore and JE subscore (all $P<0.05$ ). As for $\mathrm{BMI}$ and $\mathrm{BC}$, RA patients with physical dysfunction had higher $\mathrm{BF} \%$ (mean $31.05 \%$ vs. $29.02 \%, P=0.007$ ) and prevalence of overfat $(44 \%$ vs. $27 \%, P<0.001)$, lower ASMI (mean 5.73 vs. 6.11, $P<0.001)$ and higher prevalence of myopenia $(55 \%$ vs. $38 \%, P<0.001)$ than those with normal physical function, while no difference in BMl between two groups. After adjustment confounding factors, multivariate logistic regression analysis showed overfat $(O R=2.990,95 \% C l$ : 1.695-5.274) and myopenia $(O R=1.960,95 \% \mathrm{Cl}$ : 1.191-3.225) were positively associated with physical dysfunction respectively. Further compared with patients with normal fat, patients with overfat had significantly higher rates of dysfunction of all eight physical activities including dressing, rising, eating, walking, hygiene, reaching, griping and activities respectively (all $\mathrm{P}<0.01$ ), with the highest rate $57.5 \%$ in eating dysfunction and the lowest rate $38.6 \%$ in dressing dysfunction. Comparisons between patients with and without myopenia showed similar results with the highest rate $52.4 \%$ in eating dysfunction and the lowest rate $37.7 \%$ in rising dysfunction in those with myopenia.

Conclusion: Overfat and myopenia are present in near half RA patients with physical dysfunction which are associated with dysfunction of all eight physical activities especially eating.

Acknowledgement: This work was supported by National Natural Science Foundation of China (no. 81671612 and 81801606), Guangdong Natural Science Foundation (no. 2017A030313576, 2017A030310236 and 2018A030313541) and Guangdong Medical Scientific Research Foundation (no. A2017109)

Disclosure of Interests: None declared

DOI: 10.1136/annrheumdis-2019-eular.6479

\section{SAT0082 ASSOCIATIONS OF BASELINE CLINICAL AND BIOMARKER FACTORS WITH SYMPTOMS AND FUTURE DEVELOPMENT OF CLINICALLY-APPARENT RHEUMATOID ARTHRITIS IN AN ACPA POSITIVE COHORT}

Kevin D. Deane ${ }^{1}$, Sunil Nagpal ${ }^{2}$, Navin Rao ${ }^{2}$, Frederic Baribaud ${ }^{2}$,

George Vratsanos ${ }^{2}$, Eddie A. James ${ }^{3}$, Jane H. Buckner ${ }^{3}$, Gary S. Firestein ${ }^{4}$, David L. Boyle ${ }^{4}$, Sylvia Posso ${ }^{3}$, William H. Robinson ${ }^{5}$, Laurie K. Moss ${ }^{1}$,

Saman Barzideh ${ }^{1}$, Kristen Polinski ${ }^{1}$, Sergei Ivanov ${ }^{1}$, Jennifer Seifert ${ }^{1}$, V. Michael Holers ${ }^{1} .{ }^{1}$ CU Anschutz Medical Campus, Aurora, United States of America; ${ }^{2}$ Janssen Research and Development, LLC, Spring House, United States of America; ${ }^{3}$ Benaroya Research Institute at Virginia Mason, Seattle, United States of America; ${ }^{4}$ University of California San Diego, La Jolla, United States of America; ${ }^{5}$ Stanford University, Stanford, United States of America

Background: Subjects who are in the preclinical rheumatoid arthritis (RA) state can be identified through serum elevations of circulating RA-related autoantibodies, including rheumatoid factor (RF) and antibodies to citrullinated protein antigens (ACPA), prior to the clinical appearance of inflammatory arthritis (IA) and RA. Studying Preclinical RA may identify factors and pathways in disease development, and help to identify therapeutic targets for prevention. Furthermore, trials in ACPA+ subjects have been completed or are underway with the primary goal to prevent future $|A|$ RA. However, relatively few individuals have been studied through the evolution of the Preclinical ACPA+ state to Classified RA. As such there are still many gaps in the understanding of the clinical and immunologic evolution from Preclinical to Classified RA

Objectives: The study objective is to identify the clinical, environmental and immunologic factors/pathways that are associated with incident IA/RA development in individuals with serum ACPA elevations.

Methods: We created a cohort of 86 ACPA+ subjects who at their baseline study visit did not have a historical or examination (66/68 count) evidence of IA/RA. ACPA+ was defined as a serum elevation of anti-CCP3 (IgG, Inova) on $\geq 2$ occasions above the established cut-off ( $\geq 20$ units). These subjects were recruited over 18 months through community healthfair screening, ACPA testing of first-degree relatives of patients with RA, and rheumatology clinics. Clinical, environmental and biomarker factors, including RF $\operatorname{IgA}$ and $\lg \mathrm{M}$ [Inova] and high-sensitivity C-reactive protein [hsCRP], were assessed at the baseline visit. Herein we present interim analyses of baseline visits on the whole ACPA+ cohort and longitudinal follow-up on a subset of subjects, with a specific focus on factors that are associated with baseline symptoms and subsequent incident IA/RA. Results: At baseline, the 86 ACPA+ subjects were a mean age of 58 , $66 \%$ female, $82 \%$ were Caucasian, and $40 \%$ self-reported no joint pain, morning stiffness or fatigue. hsCRP positivity ( $>3 \mathrm{mg} / \mathrm{L}$ ) was associated with increased rates of self-reported fatigue of $>0$ on VAS $(20 \%$ vs.
$41 \%, p=0.04)$. Ever smoking was associated with increased rates of selfreported morning joint stiffness (18\% vs $50 \%, \mathrm{p} \leq 0.01)$. In addition, in analyses of longitudinal follow-up data available to date, 10/86 subjects (12\%) developed IA classified as RA (2010) a median of 293 days after baseline visit. At baseline, individuals with incident RA exhibited a higher BMI compared to those who did not (27 vs. $32, p=0.03)$. In addition, positivity for hsCRP and RF, and higher median anti-CCP3 levels, were present in those who developed incident IA/RA although not statistically significant.

Conclusion: Within this new cohort of prospectively followed ACPA+ individuals, smoking and an elevated hsCRP are associated with clinical symptoms of stiffness and fatigue, respectively. The relationship of stiffness and smoking suggests this factor is related to early joint symptoms, and the association of high BMI with incident RA may indicate this is a modifiable risk factor for RA (de Hair 2013). This prospective study will continue, with further study of the factors/pathways that may influence well-being in ACPA+ individuals as well as may influence predictive of or causally linked to the future IA/RA.

Disclosure of Interests: Kevin D. Deane Grant/research support from: Janssen, Consultant for: Janssen, Sunil Nagpal Shareholder of: Johnson \& Johnson, Employee of: Janssen Research \& Development, LLC, Navin Rao Shareholder of: Johnson \& Johnson, Employee of: Janssen Research \& Development, LLC, Frederic Baribaud Shareholder of: Johnson \& Johnson, Employee of: Janssen Research \& Development, LLC George Vratsanos Shareholder of: Johnson \& Johnson, Employee of Janssen Research and Development, LLC, Eddie A. James Grant/ research support from: Janssen, Jane H. Buckner Grant/research support from: Janssen, Gary S. Firestein Grant/research support from: Janssen, David L. Boyle Grant/research support from: Janssen, Sylvia Posso Grant/research support from: Janssen, William H. Robinson Grant/research support from: Janssen, Laurie K. Moss Grant/research support from: Janssen, Saman Barzideh Grant/research support from: Janssen, Kristen Polinski Grant/research support from: Janssen, Sergei Ivanov: None declared Jennifer Seifert Grant/research support from: Janssen, V. Michael Holers Grant/research support from: Janssen, Consultant for: Janssen DOI: 10.1136/annrheumdis-2019-eular.1297

\section{SAT0083 PREVALENCE OF FRAILTY AND ITS ASSOCIATED FACTORS IN PATIENTS WITH RHEUMATOID ARTHRITIS: A CROSS-SECTIONAL ANALYSIS}

Marco DI Carlo ${ }^{1}$, Sonia Farah ${ }^{1}$, Eleonora DI Donato ${ }^{1}$, Marina Carotti ${ }^{2}$,

Fausto Salaffi'. '1 Hospital "Carlo Urbani" clinica reumatologica, Dipartimento scienze cliniche e molecolari, Jesi, Italy; ${ }^{2}$ Ospedali Riuniti Torrette Di Ancona, Dipartimento Radiologia, Torrette, Ancona, Italy

Background: The concept of frailty is a recent issue in the rheumatologic field, by now, the prevalence of frailty among individuals with rheumatoid arthritis (RA) has not been extensively examined and few studies on frailty in RA adults have been conducted. Moreover, the relationship between frailty and sociodemographic or disease characteristics in RA are unknown. Objectives: The aims of the present research were to assess the prevalence of frailty and its potential associated factors in adult patients with RA. Methods: Consecutive RA patients and healthy controls were assessed according the Survey of Health, Ageing and Retirement in Europe Frailty Instrument (SHARE-FI) (1), and classified as frail, pre-frail or non-frail. Patients underwent to a clinimetric assessment in order to establish disease activity (Simple Disease Activity Index [SDAI]), function (Health Assessment Questionnaires Disability Index [HAQ-DI]), comorbidities (modified Rheumatic Disease Comorbidity Index [mRDCl])(2), and radiographic damage (Simple Erosion Narrowing Score [SENS]). Chi-square, analysis of variance (ANOVA), and multinomial logistic regression analyses were used to test the prognostic value of frailty for the outcomes of interest.

Results: 210 consecutive RA patients were included (72 male, 138 female) and the mean age was 60.4 years. The study group was com posed by 100 healthy controls (63 females and 47 males). The mean age was 59.1. According to SHARE-FI criteria, 35 RA patients (16.6\%) were categorized as frail, $68(32.4 \%)$ as pre-frail, and $107(51 \%)$ as nonfrail, while 8 control subjects were categorized as frail, (8\%), 17 as prefrail $(17 \%)$, and 75 as non-frail $(75 \%$ ) (chi-squared $12.8 ; \mathrm{p}=0.0016$ ). The results from logistic regression analysis revealed that age (odd ratio [OR] $=1.12,95 \%$ confidence interval $[\mathrm{Cl}]=1.07-1.17 ; \mathrm{P}<0.0001)$, comorbid ities $(\mathrm{OR}=1.51,95 \% \mathrm{Cl}=1.01-2.27 ; \mathrm{P}=0.0446)$, and high disease activity $(\mathrm{OR}=1.10,95 \% \mathrm{Cl}=1.04-1.16 ; \mathrm{P}=0.0006)$ were independ ently associated with frailty in RA patients (Fig 1).

Conclusion: Frailty or pre-frailty are common in RA. The SHARE-FI may be a specific tool for the screening of frailty in RA and may summarize 